\title{
Intermediate-term results of a prospective, multicenter study on remote programming sacral neuromodulation for refractory overactive bladder
}

\author{
Yaoguang Zhang ${ }^{1,2 \#}$, Lingfeng Meng ${ }^{1,2 *}$, Peng Zhang ${ }^{3 *}$, Xiaojun Tian ${ }^{4}$, Guoqing Chen ${ }^{5}$, Yan $\mathrm{Li}^{6}$, \\ Yong Zhang ${ }^{7}$, Zhihui $\mathrm{Xu}^{8}$, Zhongqing Wei', Wei Zhang ${ }^{2}$, Lulin $\mathrm{Ma}^{4}$, Benkang Shi ${ }^{6}$, Limin Liao ${ }^{5}$, \\ Jianye Wang ${ }^{1,2}$
}

${ }^{1}$ Urology Department, Beijing Hospital, National Center of Gerontology, Institute of Geriatric Medicine, Chinese Academy of Medical Sciences Beijing, China; ${ }^{2}$ Peking University Fifth School of Clinical Medicine, Beijing, China; ${ }^{3}$ Urology Department, Beijing Chaoyang Hospital, Capital Medical University, Beijing, China; ${ }^{4}$ Urology Department, Peking University Third Hospital, Beijing, China; ${ }^{5}$ Urology Department, China Rehabilitation Research Center, Beijing, China; ' Urology Department, Qilu Hospital, Shandong University, Jinan, China; ${ }^{7}$ Urology Department, Beijing Tiantan Hospital, Capital Medical University, Beijing, China; ${ }^{8}$ Urology Department, Zhejiang Provincial People’s Hospital, Hangzhou, China; ${ }^{9}$ Urology Department, Second Affiliated Hospital of Nanjing Medical University, Nanjing, China

Contributions: (I) Conception and design: All authors; (II) Administrative support: Y Zhang, P Zhang, Y Zhang, Z Xu, Z Wei, L Ma, B Shi, L Liao, J Wang; (III) Provision of study materials or patients: Y Zhang, L Meng, P Zhang, X Tian, G Chen, Y Li, Y Zhang, Z Xu, Z Wei; (IV) Collection and assembly of data: Y Zhang, L Meng, P Zhang; (V) Data analysis and interpretation: Y Zhang, L Meng, P Zhang; (VI) Manuscript writing: All authors; (VII) Final approval of manuscript: All authors.

\#These authors contributed equally to this work.

Correspondence to: Dr. Jianye Wang. Urology Department, Beijing Hospital, No.1 DaHua Road, Dong Dan, Beijing 100730, China.

Email: jywangbjhospital@126.com.

Background: To evaluate the efficacy and safety of a novel remote programming sacral neuromodulation (SNM) system (BetterStim system) in the treatment of patients with refractory overactive bladder (OAB) for 3 years.

Methods: A total of 8 centers in China enrolled 84 patients with OAB. Following test stimulation 70 patients underwent implantation using BetterStim. All patients returned for follow-up at 3 and 6 months postoperatively. After that, the visits were conducted by telephone. Outcomes of voiding diaries, the overactive bladder symptom score (OABSS), questionnaires regarding OAB-related quality of life (OABqol), and adverse events (AEs) were evaluated at each visit. The clinical therapeutic success was defined as $\geq 50 \%$ improvement from baseline in any of the voiding diary variables or average voids/day return to normal voiding ( $<8$ voids/day). The analysis is a modified Completers analysis.

Results: At the 36-month follow-up, the success rate was 79\% for overall OAB symptoms, $69 \%$ for urge urinary incontinence (UUI) and $42 \%$ for urgency frequency (UF). The average number of voids/ day decreased from $29.2 \pm 14.9$ at baseline to $17.6 \pm 11.2$ at 3 years, the average volume/void increased from $94.7 \pm 54.2$ to $151.4 \pm 80.8 \mathrm{~mL}$, the urgency reduced from $3.0 \pm 1.4$ to $1.8 \pm 1.7$ (all $\mathrm{P}<0.001$ ). For patients with urge incontinence, mean leaking episodes/day decreased from $8.1 \pm 7.6$ at baseline to $2.1 \pm 3.5$ at three years $(\mathrm{P}<0.05)$. The devices were explanted in $8(11.4 \%)$ patients. There were no remote programming-related AEs or device-related serious AEs that occurred.

Conclusions: The Intermediate-term results demonstrated that BetterStim SNM system with remote programming is safe and effective for patients with refractory OAB.

Keywords: Sacral neuromodulation (SNM); remote programming; overactive bladder (OAB)

Submitted Jan 18, 2021. Accepted for publication Mar 23, 2021.

doi: $10.21037 /$ tau-21-43

View this article at: http://dx.doi.org/10.21037/tau-21-43 


\section{Introduction}

Sacral neuromodulation (SNM) is a minimally invasive, effective means of treating refractory overactive bladder $(\mathrm{OAB})$. Although studies have shown that SNM is effective in refractory $\mathrm{OAB}(1-3)$, for optimal relief, patients will require reprogramming of their neuromodulation device $(4,5)$. The standard current protocol involves patients coming into clinic, however, this may be a barrier to healthcare due to time and costs of traveling.

Currently, a novel SNM system called BetterStim system has been manufactured by Beijing PINS Medical Co., Ltd. (PINS), which provides two kinds of programming methods. Besides the conventional face-to-face programming, it can also achieve real-time remote programming. The remote programming system is a secure and robust Internet-based system, involving in the application of a virtual network combined with point-to-point encryption software that meets recognized standards, which was refined and well described previously (6-8). Compared with conventional programming, remote programming allows patients to reprogram through the Internet or mobile phone $4 \mathrm{G}$ network without leaving home. It may provide a solution to addressing clinic visits for programming.

In order to evaluate the safety and effectiveness of BetterStim system, we designed a clinical trial, which was divided into two stages. The first stage was a prospective, controlled, multicenter trial comparing SNM to standard medical therapy at 3 and 6 months. Short term results for urinary symptom relief with BetterStim are promising (8). The second stage is an evaluation of the safety and effectiveness of SNM for 5 years. The purpose of this report is to describe the results of three-year follow-up. We present the following article in accordance with the STROBE reporting checklist (available at http://dx.doi. org/10.21037/tau-21-43).

\section{Methods}

Detailed study design, inclusion and exclusion criteria, implantation procedure, and follow-up visits have been previously published (8). Subjects had a primary diagnosis of $\mathrm{OAB}$ as demonstrated on a 5-day voiding diary defined as $\geq 8$ voids/day (urgency frequency, UF), and/or a minimum of 2 involuntary leaking episodes in $72 \mathrm{~h}$ period (urge urinary incontinence, UUI). Patients experienced previous treatments failure with at least one anticholinergic medication or could not tolerate more conservative treatments. All the procedures performed in this study were in accordance with the Declaration of Helsinki (as revised in 2013) and approved by the Ethics Committee of Beijing Hospital (NO.: 2015BJYYEC-08-04). All subjects signed informed consent prior to participating. All subjects underwent a two-stage procedure with the BetterStim system (neurostimulator models G131/G132, lead model L331; PINS, Beijing, China). Test stimulation success was considered as $\geq 50 \%$ improvement from baseline in key voiding variables [either in average voids/day or a return to normal voiding ( $<8$ voids/day) or average leaks/day] based on voiding diaries. After completion of test stimulation ( 2 weeks), those who met success criteria were implanted permanently with the neuromodulator.

Demographic and clinical data were collected at the time of presentation. Postoperative follow-up burden was evaluated by the self-designed questionnaires (seen in the Appendix 1) (7). All patients were returned for visits at 1,3 , and 6 months postoperatively. After that, patients were followed up by telephone at 12, 24 and 36 months. Unscheduled follow-up was conducted for patients who needed to reprogram. At each visit, we would adjust stimulation parameters according to the needs of patients. Adjustments may include stimulation amplitude, frequency, pulse width, etc. Voiding diaries, the $\mathrm{OAB}$ symptom score (OABSS) questionnaire (9), and OAB-related quality of life (OAB-qol) were collected to evaluate the response to treatment. OAB-qol was accessed using the validated International Consultation on Incontinence Modular Questionnaire (ICIQ)-OABqol (10), which was measured on a scale [0-10] with an interference question, "Overall, how much do your urinary symptoms interfere with your everyday life?" According to the difference between the follow-up and baseline, the interference is classified as follows: worsened ( $\geq 2)$, no change ( -1 to 1 ), improved ( -4 to -2$)$, and greatly improved ( $\leq-5)$ (3). During the visits, all adverse events (AEs), defined as device-related AEs, stimulation-related AEs or remote programming-related AEs, were documented.

\section{Statistical analysis}

Various outcome measures were evaluated to determine the 3-year efficacy of SNM, including success rates (OAB, UF, UUI subgroups) and absolute change in the key voiding variables, including voiding frequency, voiding volume, degree of urgency [rated on the scale (0-5): $0=$ no urgency, 
Table 1 Subjects' baseline demographics

\begin{tabular}{|c|c|}
\hline Variables & $\mathrm{n}(\%)$ \\
\hline \multicolumn{2}{|l|}{ Gender } \\
\hline Female & $51(72.9)$ \\
\hline Male & $19(27.1)$ \\
\hline Median age at consent (IQR) (years) & $55.42(41.22-65.05)$ \\
\hline \multicolumn{2}{|l|}{ OAB qualification per diary } \\
\hline Frequency only & $1(1.4)$ \\
\hline Urgency and frequency & $69(98.6)$ \\
\hline Both & $17(24.3)$ \\
\hline Baseline voids/day (mean \pm SD) & $29.15 \pm 14.88(n=70)$ \\
\hline Baseline urgency of voids ${ }^{\dagger}($ mean $\pm S D)$ & $2.98 \pm 1.37(n=69)$ \\
\hline Baseline leaks $/$ day $^{\ddagger}($ mean \pm SD $)$ & $8.14 \pm 7.59(n=17)$ \\
\hline Baseline void volume/void (mean $\pm \mathrm{SD}, \mathrm{ml}$ ) & $94.71 \pm 54.23(n=70)$ \\
\hline $\begin{array}{l}\text { Duration of symptoms before SNM (mean } \\
\pm \mathrm{SD} \text {, years) }\end{array}$ & $6.53 \pm 5.30$ \\
\hline \multicolumn{2}{|l|}{ Medical history } \\
\hline Interstitial cystitis (IC) & $20(28.6)$ \\
\hline Hypertension & $13(18.6)$ \\
\hline Benign prostatic hyperplasia & $5(7.1)$ \\
\hline Diabetes & $6(8.6)$ \\
\hline Urinary tract infections & $4(5.7)$ \\
\hline Lumbar disc herniation & $5(7.1)$ \\
\hline Others & $16(22.9)$ \\
\hline $\begin{array}{l}\text { Travel distance from home to clinic (mean } \\
\pm \mathrm{SD}, \mathrm{km} \text { ) }\end{array}$ & $1,364.98 \pm 764.93$ \\
\hline \multicolumn{2}{|l|}{ Cost to every trip to clinic $(n=68, R M B)$} \\
\hline$<200$ & $20(29.4)$ \\
\hline $200-500$ & $12(17.7)$ \\
\hline $500-1,000$ & $4(5.9)$ \\
\hline$>1,000$ & $32(47.0)$ \\
\hline \multicolumn{2}{|c|}{ Average interval of clinical visits ( $n=68$, time/month) } \\
\hline$<1$ & $30(44.1)$ \\
\hline $1-3$ & $6(8.8)$ \\
\hline $4-6$ & $16(23.5)$ \\
\hline$>7$ & $16(23.5)$ \\
\hline
\end{tabular}

${ }^{\dagger}$, Urgency of voids was rated on the scale (0-5): $0=$ no urgency, $5=$ very severe. And only patients with a score other than 0 were counted. " Leaks/day includes only those patients who qualified for UUI at baseline. OAB, overactive bladder; SNM, sacral neuromodulation; UUI, urge urinary incontinence.
$5=$ very severe], and leaking. The analysis is a modified Completers analysis. For patients who explanted due to device-related AEs or loss of efficacy, their missing data imputed to their baseline assessment and were therefore considered failures. Patients who explanted unrelated to the device were excluded. For patients who missed the scheduled visits, the last observation results were used to estimate the missing data. The continuous variables are summarized by means and standard deviations (SD). Wilcoxon signed-rank test was used to show the $\mathrm{P}$ values for paired comparison of the key voiding variables, OABSS, and $\mathrm{OAB}$-qol between baseline and follow-up visits. A value of $\mathrm{P}<0.05$ is considered to be statistically significant. The IBM SPSS ${ }^{\circledR}$ Statistics (version: 20) was used for all analyses.

\section{Results}

In total, 84 subjects with $\mathrm{OAB}$ completed test stimulation, and 70 patients, mean age $52.8 \pm 15.6$, received a full system implant. Subjects' baseline demographics are shown in Table 1. The average follow-up time was $35.0 \pm 14.0$ months. A total of 69 patients were followed up for 3 months, 65 for 6 and 12 months, 55 for 24 months, and 47 for 36 months. A total of 8 patients had their device permanently removed. Four of them were removed within 3 months after implantation due to intolerable feelings of irritation, lead fracture, capsular exudate, and cystectomy, respectively, and four patients were removed about a year after surgery due to ineffectiveness. Figure 1 shows an overview of the research procedures.

At the 36-month follow-up, the success rate was 79\% for overall OAB symptoms, $69 \%$ for UUI and $42 \%$ for UF (Figure 2). The average number of voids/day decreased from $29.2 \pm 14.9$ at baseline to $17.6 \pm 11.2$ at 3 years, the average volume/void increased from $94.7 \pm 54.2$ to $151.4 \pm$ $80.8 \mathrm{~mL}$, the urgency reduced from $3.0 \pm 1.4$ to $1.8 \pm 1.7$ (Figure $3 A, B, C$, all $\mathrm{P}<0.001$ ). For patients with urge incontinence mean leaking episodes/day decreased from $8.1 \pm 7.6$ to $2.1 \pm 3.5$ (Figure $3 D, \mathrm{P}<0.05$ ). And at least $6 / 17$ patients had complete continence during the follow-up for 3 to 36 months. At the 3-month follow-up, six patients had basically returned to normal voiding. And at the 36-month follow-up, the number increased to 9. Three of these patients have maintained normal voiding for 3 years.

Both OABSS and OAB-qol at different follow-up (Figure $4 A, B$, both $\mathrm{P}<0.001$ ) suggested a significant improvement for patients and the scores decreased continuously with the time interval. At the 36-month 


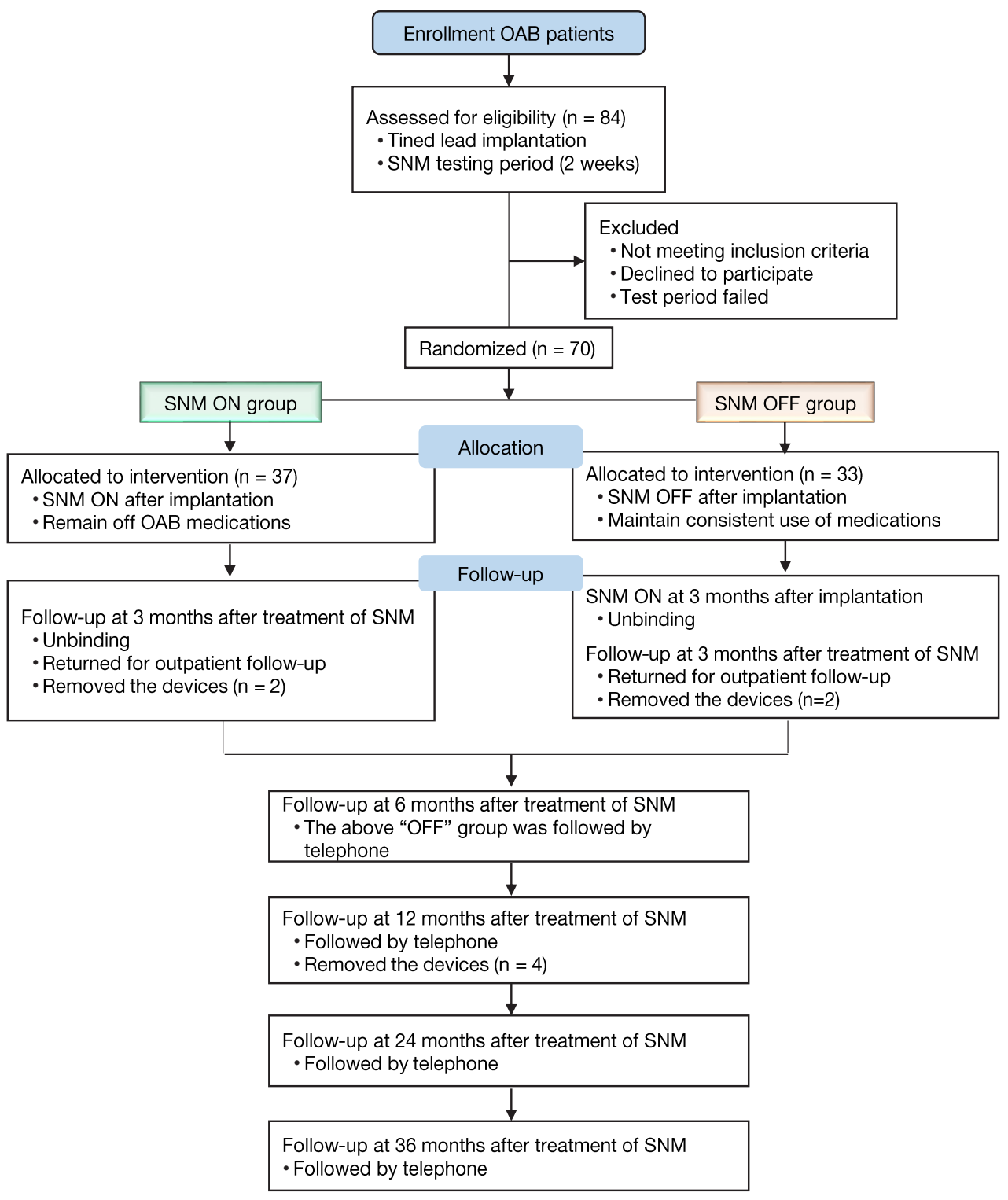

Figure 1 The overview of the procedures in this study.

follow-up, $82 \%$ of patients reported an improved or greatly improved in urinary symptom interference score (Figure 4C).

Considering the importance of programming postoperatively in maintaining the efficacy of SNM, we obtained information about patients' programming from the database of PINS. The number of programming events decreases with time interval, but the proportion of remote programming increases. There were 221 programming events in the first year, of which remote programming accounted for $60.5 \%$. There were 79 programming events in the second year, of which remote programming accounted for $69.6 \%$. And in the third year, there were only 38 programming events, of which remote programming accounted for $78.9 \%$. At the last follow-up, nearly $90 \%$ $(62 / 70)$ of the patients experienced remote programming and were satisfied with it.

During the 3-year follow-up, $14.3 \%$ (10/70) of patients reported device-related AEs. There were no remote programming-related AEs or device-related serious AEs that occurred. The most common types of AEs reported 
A

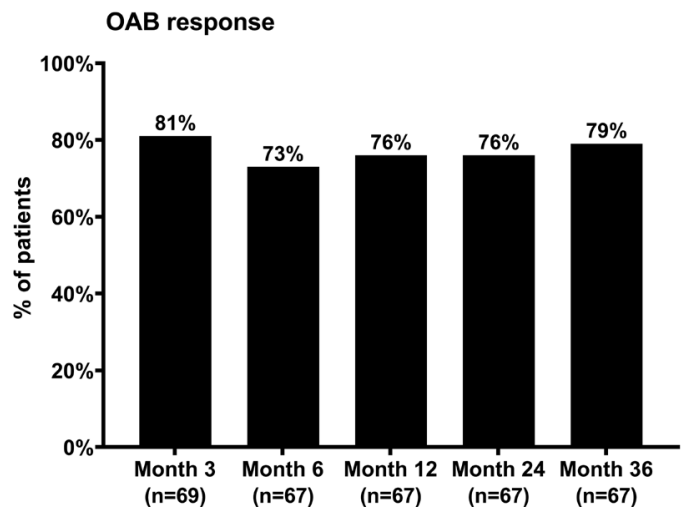

B

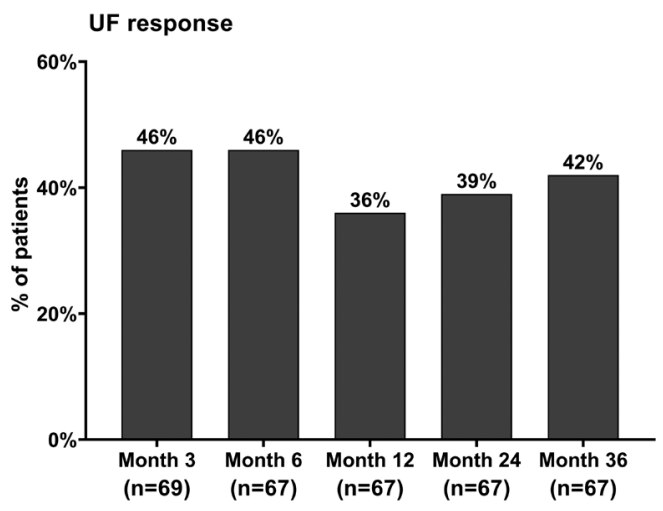

C

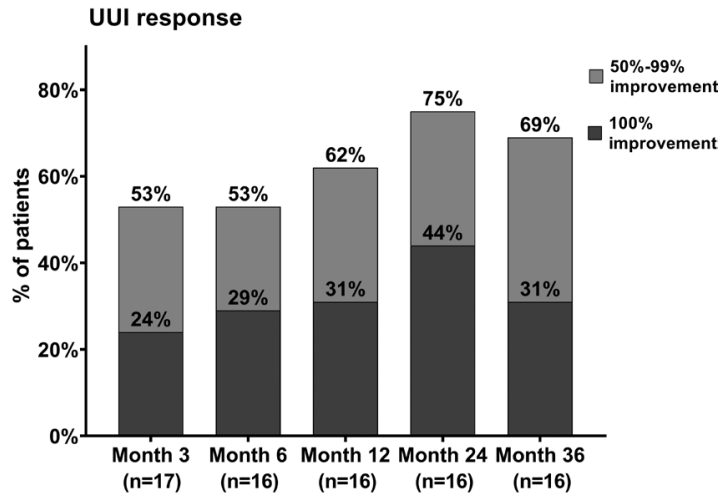

Figure $2 \mathrm{OAB}$ therapeutic success rate over time. (A) $\mathrm{OAB}$ response, defined as either $\geq 50 \%$ improvement in any of the symptoms (frequency, urgency, and/or urge urinary incontinence) or average voids/day return to normal voiding ( $<8$ voids/day). (B) UF response, defined as $\geq 50 \%$ improvement in voids/day or average voids/day return to normal voiding ( $<8$ voids/day). (C) UUI response, defined as $\geq 50 \%$ improvement in leaks/day; analysis only for patients with UUI. OAB, overactive bladder; UUI, urge urinary incontinence; UF, urgency frequency. were undesirable change in stimulation $(10 / 70,14.3 \%)$, loss of efficacy $(8 / 70,11.4 \%)$, and pain at the implantation site $(5 / 70,7.1 \%)$. A total of $8(11.4 \%)$ patients explanted the devices. None of the patients underwent surgical intervention due to battery depletion or lead migration.

\section{Discussion}

SNM is a well-established, minimally invasive method for the treatment of refractory OAB. This study demonstrates sustained safety and effectiveness of the novel remote programming SNM in patients with refractory OAB. Follow-up for 36 months, the success rate was kept close to $80 \%$, and the improvement in each of the key variables in voids diary, OABSS, and OAB-qol was sustained. The therapeutic effect of our study is similar to that of previous reports $(17-90 \%)(2,3,11-16)$. The incidence of devicerelated AEs (14.3\%) and the explantation rate $(11.4 \%)$ in our study were lower than those in other studies (13,17-19).

In our study, the average number of voids per day at baseline was 29.15, which is high for OAB patients. We think that the main reasons for this may be as follows. First of all, Chinese people have a relatively high tolerance for suffering. Most patients come to the hospital only when their symptoms are relatively serious, and the patients in our study are no exception. Secondly, there is a treatment method in China called acupuncture. Acupuncture can effectively improve the symptoms such as urgency, frequency, and nocturia (20), but it is cheaper than SNM. Therefore, patients with $\mathrm{OAB}$ symptoms prefer receiving treatment with acupuncture first and then further seek invasive surgical treatment after the effect of acupuncture is poor, which will undoubtedly intercept some patients with relatively mild symptoms. However, the curative effect of acupuncture was correlated to anxiety (21). The milder the anxiety level was, the better the therapeutic effect would be. Patients with $\mathrm{OAB}$, especially those with interstitial cystitis (IC), are often accompanied by severe anxiety. Therefore, some patients attempt SNM after acupuncture treatment has failed. This may lead to the fact that the patients in our study had severe symptoms before receiving SNM, and the proportion of patients with IC was high.

In our study, the common types of reported AEs were undesirable change in stimulation $(10 / 70,14.3 \%)$, loss of efficacy $(8 / 70,11.4 \%)$, and pain at the implantation site $(5 / 70,7.1 \%)$. A total of $8(11.4 \%)$ patients underwent 
A

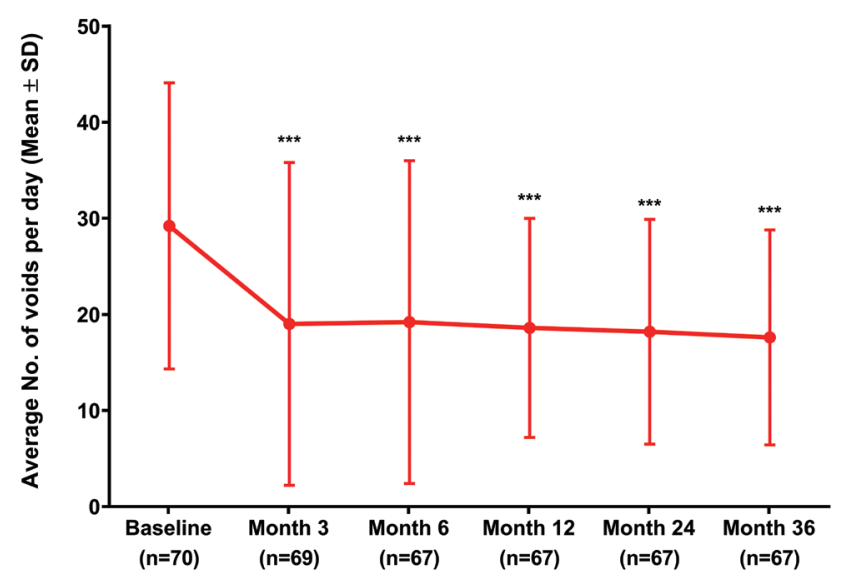

C

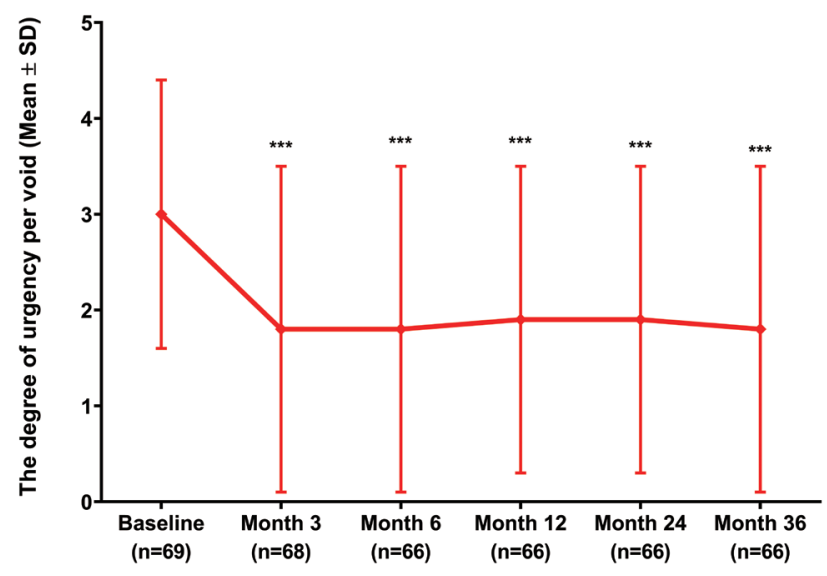

B
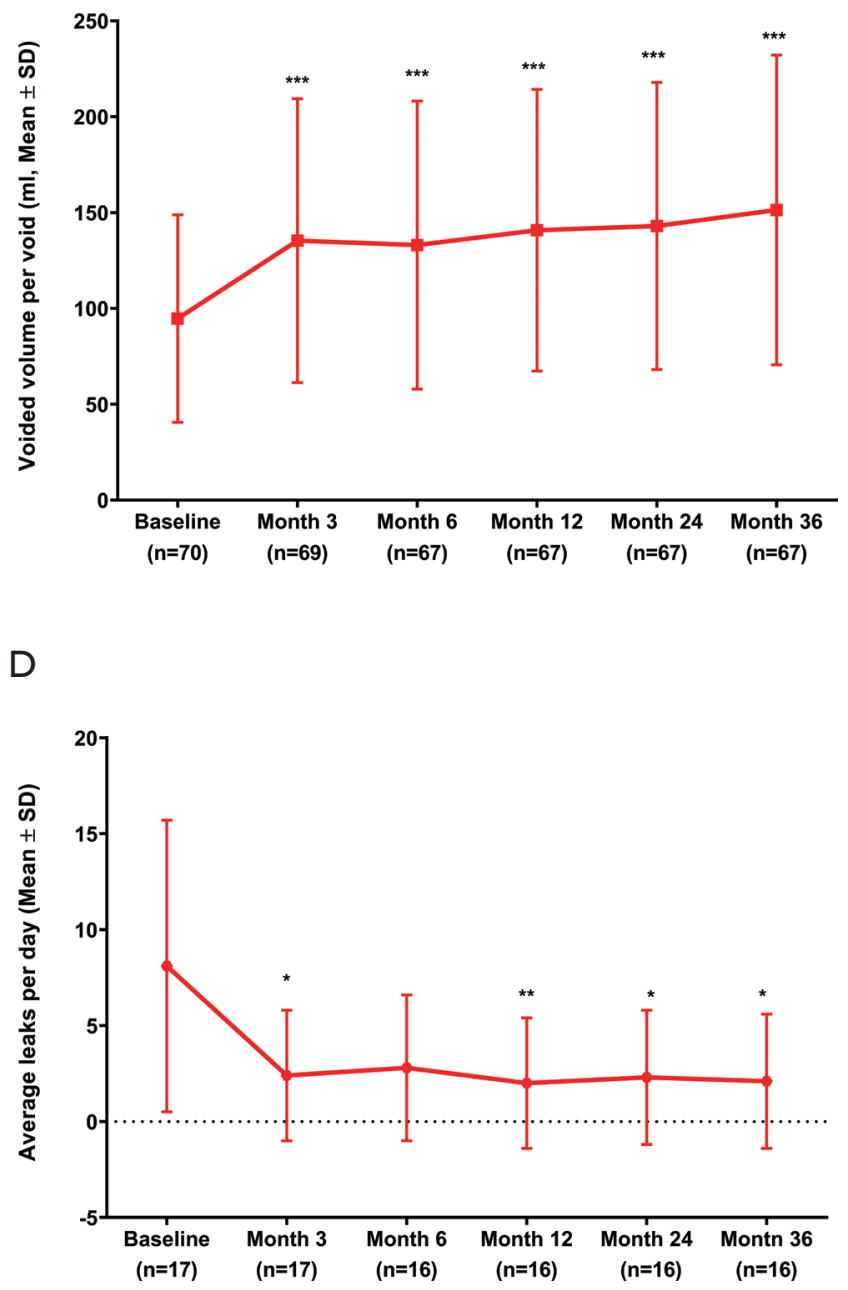

Figure 3 Average voiding diary parameters for 36 months after treatment. (A) Average No. of voids per day. (B) Voided volume per void. (C) The degree of urgency per void [urgency of voids was rated on the scale (0-5): $0=$ no urgency, $5=$ very severe; Only patients with a score other than 0 at baseline were counted). (D) Average leaks per day (Only patients with UUI at baseline were included). ${ }^{*} \mathrm{P}<0.05,{ }^{* *} \mathrm{P}=0.001$, *** $\mathrm{P}<0.001$ for significant difference between follow-up visit and baseline.

device removal. The most common reason was the loss of efficacy, which is similar to that reported in literature (22). With the prolongation of follow-up time, the loss of efficacy has gradually become a mainstream issue in SNM treatment. For these patients with recurrent symptoms or weakening of the degree of symptom improvement over time, existing treatments include combining oral drugs, adjusting the stimulation parameters, such as frequency, voltage/pulse duration. Among these parameters, the stimulation frequency may be an important parameter for the success of treatment. Recently, a new stimulation mode of SNM therapy, variable frequency stimulation (VFS), was introduced by PINS. Compared with the traditional constant frequency stimulation (CFS) mode, the VFS can realize alternate stimulation of 1-5 different frequency in the same program group. In our pre-experiment, the VFS showed satisfactory improvement of symptoms in $\mathrm{OAB}$ patients with recurrent symptoms or weakening of the degree of symptom improvement (23). However, the mechanism and long-term effectiveness of VFS are still unclear, and large sample size trials are still needed to provide more convincing evidence. 
A

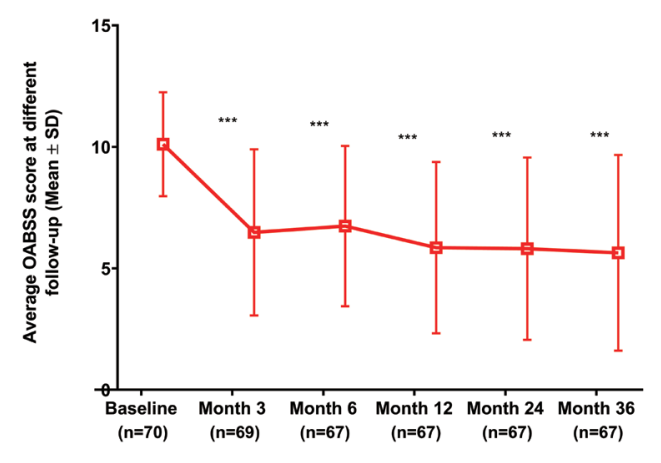

B
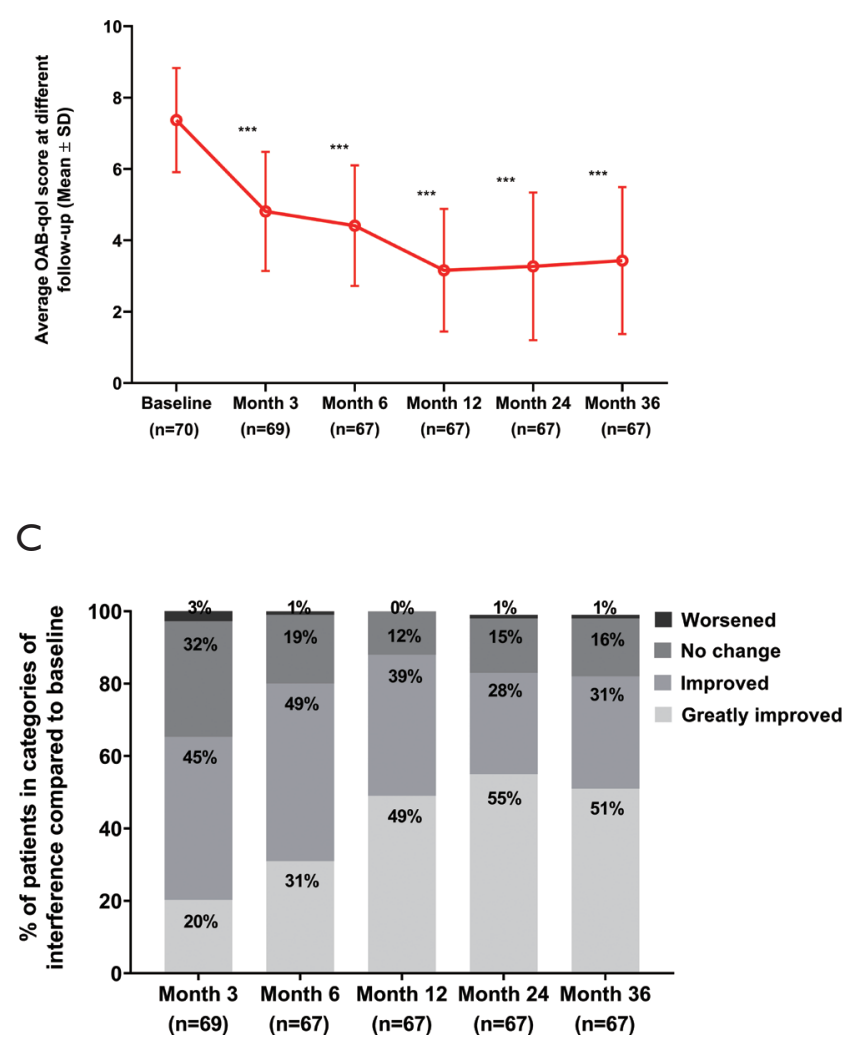

Figure 4 Symptom score and subjective evaluation at different follow-up visits. (A) Average OABSS score at different follow-up. (B) Average OAB-qol score at different follow-up. (C) Percent of patients in categories of interference compared to baseline. Categories: worsened $(\geq 2)$, no change ( -1 to 1$)$, improved ( -4 to -2$)$, and greatly improved $(\leq-5)$. ${ }^{* * *} \mathrm{P}<0.001$ for significant difference between follow-up visit and baseline.
Follow-up to 36 months, none of the patients had received surgical intervention due to battery depletion. As a recharge-free system, the long battery life of BetterStim system would reduce the number of device replacements, reduce surgical risks and provide cost savings. According to PINS, under typical clinical use (3 V, $210 \mu \mathrm{s}, 14 \mathrm{~Hz}$, $1 \mathrm{k}$ load, continuous stimulation), the battery of G131 would last 7.9 years, and the battery of G132 would last 5.5 years, which are 2.1 times and 1.5 times of the service life of InterStim II, respectively. Recently, in order to provide more benefits to patients, the rise of rechargeable SNM system has become a trend. Axonics modulation technologies, Inc. launched a rechargeable SNM systemAxonics $\mathrm{r}-\mathrm{SNM}^{\circledR}$ system, which has been approved by FDA for treating $\mathrm{OAB}$, non-obstructive urinary retention and fecal incontinence (24). With an approved functional life of at least 15 years, the Axonics System is the first rechargeable SNM system available for use in the United States (25). Later, Medtronic also launched a smaller and faster rechargeable device-InterStim ${ }^{\mathrm{TM}}$ Micro system. Two rechargeable systems are approved for full-body magnetic resonance imaging (MRI) scans (24). And research shows that they deliver the same effective results as the trusted InterSim II system for people with bladder and bow control problems (24-27).

One of the most remarkable advantages of the BetterStim system is the significant function of remote programming. On March 11, 2020, COVID-19 was declared a pandemic by the World Health Organization, in the past year, as quarantining and social distancing became the norm (28). Patients began delaying all kinds of health care amid fears of the virus. In the past year, China has experienced a decline in emergency department visits and clinic visits and a surge in digital health. For patients with LUTDs with the BetterStim system, remote programming played a great role during the COVID-19 epidemic. To evaluate the long-term effect of remote programming, we analyzed the postoperative programming events of patients. Similar to other studies, the total number of reprogramming events decreased year by year (19), but the proportion of remote programming increased from $60.5 \%$ in the first year to $78.9 \%$ in the third year. Up to the last follow-up, nearly $90 \%$ (62/70) of the patients had experienced remote programming and were prefer it to in-person ones. Our patients are very satisfied with remote programming, which 
benefits from the advantages of remote programming, including removing the need for transportation, saving time spent on travel and waiting at the clinic, reducing the expenses that are generated during office visits, and providing better confidentiality for patients.

We realized that there were a large number of patients lost to follow-up, especially in the later telephone followup. Although we collected the contact details of patients and their family members before the start of the study and obtained as comprehensive data as possible through multiple calls, patient communication, and detailed recording during each telephone follow-up, it was still impossible to avoid some patients losing the follow-up. At the last visit, $23(32.9 \%)$ patients did not complete the follow-up. Eight (34.8\%) of them did not receive data collection due to device removal. Eleven $(47.8 \%)$ of them could not be contacted due to changing phone numbers/phone outages. Other patients refused to provide data for various reasons. The feasibility of telephone interviews has been proven $(29,30)$. There are many advantages of telephone follow-up interviews, including flexibility, relatively cheapness, high response rates (30), but it still needs sufficient technology and resources to play its best role.

There are still some limitations that need to be pointed out. The number of patients lost to follow-up was high (33\% in three years). Although we have adopted the modified Completers analysis, it may still have impacts and bias towards the results. This study was carried out in multiple centers, the operating proficiency of surgeons and the postoperative management of patients in each center was different, which would affect the treatment effect. With the popularization of SNM in China, it is believed that SNM will be applied in more centers, and patient management will become more and more standardized.

\section{Conclusions}

In this paper, the results of the follow-up for 36 months are evaluated. The results demonstrate that the BetterStim system with remote programming technology (PINS, Beijing, China) is effective and safe for patients with refractory $\mathrm{OAB}$. We will continue to follow-up these patients and evaluate the long-term efficacy and safety.

\section{Acknowledgments}

Thanks to Beijing PINS Medical Co., Ltd. for the support to obtain comprehensive information on patients' programming events.

Funding: This work was supported by the National Key Research \& Development Program of China [grant number 2016YFC0105505].

\section{Footnote}

Reporting Checklist: The authors have completed the STROBE reporting checklist. Available at http://dx.doi. org/10.21037/tau-21-43

Data Sharing Statement: Available at http://dx.doi. org/10.21037/tau-21-43

Peer Review File: Available at http://dx.doi.org/10.21037/ tau-21-43

Conflicts of Interest: All authors have completed the ICMJE uniform disclosure form (available at http://dx.doi. org/10.21037/tau-21-43). The authors have no conflicts of interest to declare.

Ethical Statement: The authors are accountable for all aspects of the work in ensuring that questions related to the accuracy or integrity of any part of the work are appropriately investigated and resolved. All the procedures performed involving human participants were conducted in accordance with the ethical standards of the institutional and national research committee and with Declaration of Helsinki (as revised in 2013). The study was approved by the Ethics Committee of Beijing Hospital (No.: 2015BJYYEC-08-04) and informed consent was taken from all individual participants.

Open Access Statement: This is an Open Access article distributed in accordance with the Creative Commons Attribution-NonCommercial-NoDerivs 4.0 International License (CC BY-NC-ND 4.0), which permits the noncommercial replication and distribution of the article with the strict proviso that no changes or edits are made and the original work is properly cited (including links to both the formal publication through the relevant DOI and the license). See: https://creativecommons.org/licenses/by-nc-nd/4.0/.

\section{References}

1. Brazzelli M, Murray A, Fraser C. Efficacy and safety of sacral nerve stimulation for urinary urge incontinence: a 
systematic review. J Urol 2006;175:835-41.

2. van Kerrebroeck PEV, van Voskuilen AC, Heesakkers JPFA, et al. Results of Sacral Neuromodulation Therapy for Urinary Voiding Dysfunction: Outcomes of a Prospective, Worldwide Clinical Study. J Urol 2007;178:2029-34.

3. Siegel S, Noblett K, Mangel J, et al. Three-year Follow-up Results of a Prospective, Multicenter Study in Overactive Bladder Subjects Treated With Sacral Neuromodulation. Urology 2016;94:57-63.

4. Latini JM, Alipour M, Kreder KJ Jr. Efficacy of sacral neuromodulation for symptomatic treatment of refractory urinary urge incontinence. Urology 2006;67:550-3; discussion 3-4.

5. Amundsen CL, Richter HE, Menefee SA, et al. OnabotulinumtoxinA vs Sacral Neuromodulation on Refractory Urgency Urinary Incontinence in Women: A Randomized Clinical Trial. JAMA 2016;316:1366-74.

6. Chen Y, Hao H, Chen $\mathrm{H}$, et al. The study on a real-time remote monitoring system for Parkinson's disease patients with deep brain stimulators. Annu Int Conf IEEE Eng Med Biol Soc 2014;2014:1358-61.

7. Zhang P, Zhang YG, Liao LM, et al. Application of Internet+-based Tsinghua PINS Remote Tech to improve sacral neuromodulation programming procedure. Int Urol Nephrol 2019;51:627-32.

8. Zhang Y, Zhang P, Tian X, et al. Remotely programmed sacral neuromodulation for the treatment of patients with refractory overactive bladder: a prospective randomized controlled trial evaluating the safety and efficacy of a novel sacral neuromodulation device. World J Urol 2019;37:2481-92.

9. Homma Y, Yoshida M, Seki N, et al. Symptom assessment tool for overactive bladder syndrome--overactive bladder symptom score. Urology 2006;68:318-23.

10. Coyne K, Revicki D, Hunt T, et al. Psychometric validation of an overactive bladder symptom and healthrelated quality of life questionnaire: the OAB-q. Qual Life Res 2002;11:563-74.

11. Al-zahrani AA, Elzayat EA, Gajewski JB. Longterm outcome and surgical interventions after sacral neuromodulation implant for lower urinary tract symptoms: 14-year experience at 1 center. J Urol 2011;185:981-6.

12. Ismail S, Chartier-Kastler E, Perrouin-Verbe MA, et al. Long-Term Functional Outcomes of S3 Sacral Neuromodulation for the Treatment of Idiopathic Overactive Bladder. Neuromodulation 2017;20:825-9.
13. Siegel SW, Catanzaro F, Dijkema HE, et al. Long-term results of a multicenter study on sacral nerve stimulation for treatment of urinary urge incontinence, urgencyfrequency, and retention. Urology 2000;56:87-91.

14. Cardarelli S, D'Elia C, Cerruto MA, et al. Efficacy of sacral neuromodulation on urological diseases: a multicentric research project. Urologia 2012;79:90-6.

15. Groen J, Blok BF, Bosch JL. Sacral neuromodulation as treatment for refractory idiopathic urge urinary incontinence: 5-year results of a longitudinal study in 60 women. J Urol 2011;186:954-9.

16. Sukhu T, Kennelly M, Kurpad R. Sacral neuromodulation in overactive bladder: a review and current perspectives. Res Rep Urol 2016;8:193-9.

17. Noblett K, Benson K, Kreder K. Detailed analysis of adverse events and surgical interventions in a large prospective trial of sacral neuromodulation therapy for overactive bladder patients. Neurourol Urodyn 2017;36:1136-9.

18. White WM, Pickens RB, Dobmeyer-Dittrich C, et al. Incidence and Predictors of Complications with Sacral Neuromodulation. J Urol 2008;179:487.

19. Cameron AP, Anger JT, Madison R, et al. Battery explantation after sacral neuromodulation in the Medicare population. Neurourol Urodyn 2013;32:238-41.

20. Ke LP, Shen JW, Ding JS, et al. Clinical research progress of acupuncture and moxibustion treating female overactive bladder. Int J Trad Chin Med 2020;42:504-6.

21. Xie X, Jiang F, Wang X, et al. Analysis of curative effect factors in treating female overactive bladder with acupuncture. China Journal of Traditional Chinese Medicine and Pharmacy 2020;35:4722-4.

22. Peters KM, Killinger KA, Gilleran JP, et al. Predictors of reoperation after sacral neuromodulation: A single institution evaluation of over 400 patients. Neurourol Urodyn 2017;36:354-9.

23. Meng L, Diao T, Wang M, et al. Variable frequency stimulation of sacral neuromodulation in black-zone overactive bladder patients: a case report. Transl Androl Urol 2020;9:2842-7.

24. Benson K, McCrery R, Taylor C, et al. One-year outcomes of the ARTISAN-SNM study with the Axonics System for the treatment of urinary urgency incontinence. Neurourol Urodyn 2020;39:1482-8.

25. Cohn JA, Kowalik CG, Kaufman MR, et al. Evaluation of the axonics modulation technologies sacral neuromodulation system for the treatment of urinary and fecal dysfunction. Expert Rev Med Devices 2017;14:3-14. 
26. Blok B, Van Kerrebroeck P, de Wachter S, et al. Three month clinical results with a rechargeable sacral neuromodulation system for the treatment of overactive bladder. Neurourol Urodyn 2018;37:S9-S16.

27. Jottard K, Van den Broeck S, Komen N, et al. Treatment of Fecal Incontinence With a Rechargeable Sacral Neuromodulation System: Efficacy, Clinical Outcome, and Ease of Use-Six-Month Follow-Up. Neuromodulation 2020. [Epub ahead of print]. doi: 10.1111/ner.13298.

28. Ohannessian R, Duong TA, Odone A. Global Telemedicine Implementation and Integration Within

Cite this article as: Zhang $\mathrm{Y}$, Meng $\mathrm{L}$, Zhang $\mathrm{P}$, Tian $\mathrm{X}$, Chen G, Li Y, Zhang Y, Xu Z, Wei Z, Zhang W, Ma L, Shi B, Liao L, Wang J. Intermediate-term results of a prospective, multicenter study on remote programming sacral neuromodulation for refractory overactive bladder. Transl Androl Urol 2021;10(5):1966-1975. doi: 10.21037/tau-21-43
Health Systems to Fight the COVID-19 Pandemic: A Call to Action. JMIR Public Health Surveill 2020;6:e18810.

29. Deane FP, Kelly PJ, Crowe TP, et al. The feasibility of telephone follow-up interviews for monitoring treatment outcomes of Australian residential drug and alcohol treatment programs. Subst Abus 2014;35:21-9.

30. Johnson S, Seaton SE, Manktelow BN, et al. Telephone interviews and online questionnaires can be used to improve neurodevelopmental follow-up rates. BMC Res Notes 2014;7:219. 


\section{Supplementary}

\section{Self-designed questionnaire (1)}

\section{Impressions of remote program control: ( ) (single answer)}
A: very satisfaction
B: satisfaction
C: Basic satisfaction
D: poor result

\section{2: Expected program control frequency: ( ) (single answer)}
A: once per week
B: once every $1-3$ months
C: once every 3 months
D: none

3: Possible financial costs for each outpatient program control: ( ) (single answer)
A: 200 yuan
B: $200-500$ yuan
C: $500-1000$ yuan
D: more than 1000 yuan

\section{4: How remote program control can help patients: ( $\quad$ ) (multiple answers)}
A: remote control program could provide expert-level
B: timely program control
C: obviate traveling, save costs
D: improve SNM efficiency probably

\section{References}

1. Zhang P, Zhang YG, Liao LM, et al. Application of Internet+-based Tsinghua PINS Remote Tech to improve sacral neuromodulation programming procedure. Int Urol Nephrol 2019;51:627-32. 